\title{
Comparing effects of L-carnitine and sildenafil citrate on histopathologic recovery from sciatic nerve crush injury in female albino rats
}

\author{
O.I. Zedan (1), M.A. Bashandy \\ Anatomy and Embryology Department, Faculty of Medicine, Menoufia University, Egypt \\ [Received: 24 February 2021; Accepted: 12 March 2021; Early publication date: 9 April 2021]
}

Background: The sciatic nerve is a peripheral nerve and is more vulnerable to compression with subsequent short- or long-term neuronal dysfunction. The current study was designed to elucidate the possible ameliorative effect of L-carnitine and sildenafil (SIL) on sciatic nerve crush injury. We sought to determine the effects of L-carnitine, a neuroprotective and a neuro-modulatory agent, and SIL citrate, a selective peripheral phosphodiesterases inhibitor, on modulating neuro-degenerative changes due to sciatic nerve compression.

Materials and methods: The comparative effect of L-carnitine (at an oral dose of $20 \mathrm{mg} / \mathrm{kg} /$ day) or S/L citrate ( $20 \mathrm{mg} / \mathrm{kg} /$ day orally) administration for 21 days was studied in a rat model of sciatic nerve compression. Sciatic nerve sections were subjected to biochemical, histological, ultrastructure, and immunohistochemical studies to observe the effects of these treatments on neurofilament protein.

Results: The sciatic nerve crush injury group (group II) showed a significant decrease in tissue catalase (CAT), superoxide dismutase (SOD) and increase in malondialdehyde (MDA) as compared to control group $(p<0.01)$. Histological changes in the form of degenerated and vacuolated axoplasm with areas of nerve fibre loss and pyknotic nuclei were reported. The blood vessels were dilated, congested with areas of haemorrhage and mononuclear cell infiltration. Histo-morphometrically, a statistically significant reduction in the nerve fibres' number, mean axon cross-sectional area, myelin sheath thickness and a significant increase in collagen fibres' percentage $(p<0.05)$ as compared to control group. Immunohistochemically, neurofilament protein was significantly downregulated as proved by a significant reduction in mean area per cent of neurofilament expression. L-carnitine ameliorated the studied parameters through its neuroprotective effect while SIL, a selective peripheral phosphodiesterases (PDE-5) inhibitor, improved crush injury parameters but with less extent than L-carnitine. Conclusions: These findings indicate the valuable effects of L-carnitine administration compared to that of SIL citrate in alleviating the serious debilitating effects of sciatic nerve crush injury. Our results provide a new insight into the scope of neuroprotective and neuro-regenerative effects of L-carnitine in a sciatic nerve compression model. (Folia Morphol 2022; 81, 2: 421-434)

Key words: sciatic nerve, compression, L-carnitine, sildenafil citrate, histopathology, oxidative stress, immunohistochemistry 


\section{INTRODUCTION}

It is vital for the characteristic morphology of the peripheral nerve bundle to remain intact for normal autonomic, motor, and sensory nerve functions. Peripheral nerves injury results in transient or long-term neuronal dysfunction, often leading to subsequent social and economic disability [37].

The various types of nerve injuries include compression (crush), stretch, and laceration [10]. Acute traumatic peripheral nerve injury induces tissue lesions at the damaged site, such as axonal degeneration, demyelination, multifocal loss of nerve fibres, oedema in the endoneurium as well as enhanced vascular permeability with axoplasmic flow block $[8,55]$. Persistent nerve crushing can affect microcirculation which play main role in nerve regeneration, oxygen supply and maintain neural conduction [23]. Release of nerve compression (reperfusion) leads to release of nerve tissue pressure and subsequent redeposition of nutrients and oxygen in high pressure and enhances free radicals formation leading to lipid peroxidation and tissue damage $[54,71]$.

The chances of sensory function returning are still very poor even with expert surgical repair, and this may have subsequent adverse effects on motor function, particularly fine motor skills [34]. If medical treatment is not available, death can occur in the injured nerve cell, resulting in functional loss [47]. Various agents have been tested via experimental trials in an attempt to prevent this loss of motor function $[13,20]$.

Carnitine is an amine with vitamin-like characteristics and a non-amino acid structure [6]. There are two forms of carnitine: L-carnitine and its analogues. These have a protective effect against tissue ischaemia and subsequent reperfusion damage [55]. It is responsible for the transportation of fatty acids from the cytoplasm to the mitochondria, allowing adenosine triphosphate production via oxidative phosphorylation process [36]. It may also play a role in acetylcholine synthesis and release. Acetyl L-carnitine also plays a role in neuron repair and balances nerve growth factor expression in the central nervous system [63].

Researches have evaluated the neuroprotective effect of acetyl-L-carnitine in patients suffering from neuropathic pain, nerve function loss, and damaged sciatic nerve. Furthermore, marked improvement and symptom relief has been reported in these patients $[14,32,55]$.

Pettegrew et al. [51] studied the neuromodulatory and neuroprotective effects of carnitine on
Alzheimer's disease, revealing its beneficial effects on cognitive function and neurodegeneration in these patients. L-carnitine has also been shown to possess analgesic [22] and antidepressant properties [11]. Moreover, L-carnitine has been reported to play a key role in treating diabetes-induced retinopathy and neuropathy as shown by a decrease in the level of L-carnitine in the sciatic nerve. Additionally, it exerts antinflammatory activity by decreasing interleukin (IL)-6, IL-1 $\beta$, and tumour necrosis factor alpha (TNF- $\alpha$ ) levels [69] and antifibrotic activity [46].

Sildenafil (SIL) is a selective peripheral phosphodiesterases (PDE-5) inhibitor and has been shown to have a therapeutic effect in improving erectile dysfunction by increasing the level of intracellular cGMP $[25,50]$. Moreover, SIL also has a beneficial effect on several diseases [64] such as having peripheral antinociceptive properties, resulting in the accumulation of intracellular cGMP [30]. Additionally, it exacerbates the antinociceptive character of different analgesics such as morphine, celecoxib, and indomethacin via the nitric oxide-cyclic guanosine monophosphate (NO-cGMP) pathway $[17,44]$. According to the American Heart Association [5], SIL increases the level of brain neurotransmitters that enhances stroke recovery. Furthermore, it can improve the neurological effects of brain neurotransmitters when administered to rats within 2-24 hours of stroke.

The present study was designed to elucidate the possible ameliorative effect of L-carnitine and SIL on sciatic nerve crush injury. To observe these effects, we conducted histological, ultrastructure, morphometric, and quantitative immunohistochemical studies in rats administered these agents.

\section{MATERIALS AND METHODS}

\section{Animals}

In this study, 65 adult female albino rats were obtained from the Menoufia University animal house located in the Faculty of Medicine. Each rat weighed approximately 200-220 g. The rats were housed in metal cages under suitable laboratory conditions (12 h light/dark cycle, with lights on from 07:00 to 19:00). The environment was maintained a temperature of $22 \pm 2^{\circ} \mathrm{C}$ during the experimental period. The rats had access to tap water and standard food ad libitum. The study was conducted in accordance with all international guidelines for animal care. All experimental protocols and animal care were approved by the Experimental Animal Ethics Committee, Menoufia 
University, Shibin Elkom, Egypt. This experiment was prepared and designed according to guidelines approved by the Menoufia University Ethical Committee.

\section{Experimental design}

The female rats were divided into four groups.

- group I: was designated as the control group, and was subdivided into four groups ( $\mathrm{n}=5 \mathrm{rats} / \mathrm{group}$ ):

- subgroup IA, in which rats did not receive any experimental treatment through the study duration;

- subgroup IB (sham operation subgroup), in which the sciatic nerves were exposed on the right hindlimb of each rat without crushing;

- subgroup IC (L-carnitine subgroup), in which rats were orally administered with L-carnitine $(100 \mathrm{mg} / \mathrm{kg} / \mathrm{day})$ which was dissolved in distilled water for 21 days [6];

- subgroup ID (SIL citrate subgroup), in this group rats were orally administered SIL citrate $(20 \mathrm{mg} / \mathrm{kg} /$ day) which was dissolved in normal saline for 21 days [39];

- group II (sciatic nerve crush injury group): animals were subjected to sciatic nerve crush injury ( $n=15)$;

- group III (L-carnitine-treated sciatic nerve crush injury group) animals were orally administered with L-carnitine at the same dosage and schedule as subgroup IC, and were subjected to sciatic nerve crush injury $(n=15)$;

- group IV (SIL citrate-treated sciatic nerve crush injury group) animals were administered with SIL citrate at the same dosage and schedule as subgroup ID, and were subjected to sciatic nerve crush injury $(n=15)$.

The duration of the experiment was 21 days. Twenty-four hours after the final dosages were administered, rats were anesthetised with an overdose of phenobarbital via inhalation $(200 \mathrm{mg} / \mathrm{kg})$ then sacrificed by rapid cervical dislocation. The proximal segments of the sciatic nerve of the right hindlimb were obtained from each animal using scissors.

\section{Drugs and chemicals}

L-carnitine. L-carnitine base $(350 \mathrm{mg}$ ) was obtained in tablet from MEPACO-MEDIFOOD (Arab Company of Pharmaceuticals and Medicinal Plants, Sharkeya, Egypt). Each tablet was dissolved in distilled water to obtain the required dose, and was used immediately subsequent to dilution.

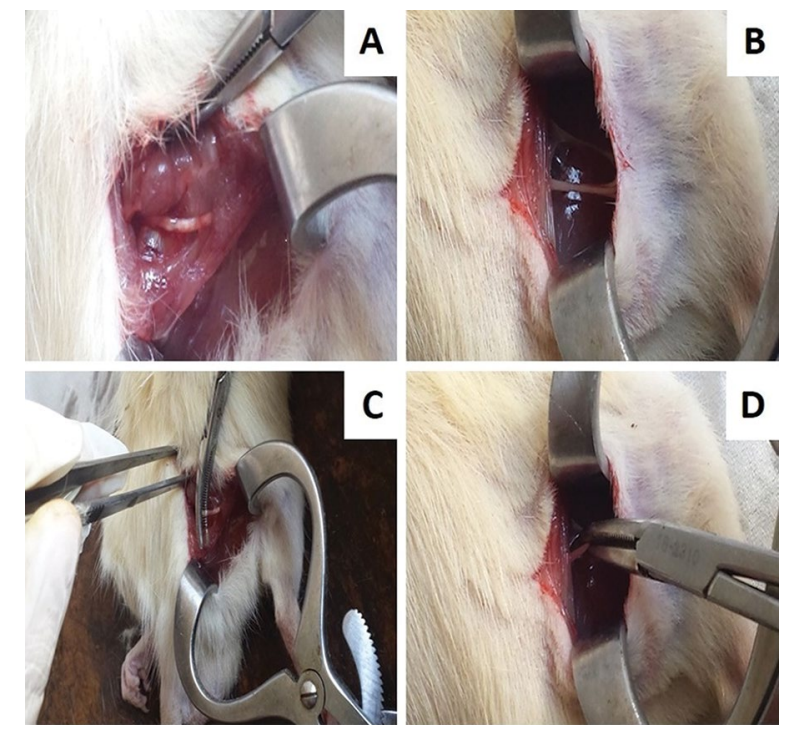

Figure 1. Exposure and compression of the sciatic nerve; A, B. Sciatic nerve exposure; C, D. Sciatic nerve compression.

Sildenafil citrate. SIL citrate (VIAGRA) was obtained in tablet form, and each tablet contained $50 \mathrm{mg}$ of the active ingredient (Pharmaco-Vigilance Centre, Pfizer Pharmaceutical Company, Dokki, Egypt). The estimated dose was suspended in normal saline.

\section{Surgical procedure}

Rats were anesthetised before surgery via intraperitoneal injection of ketamine $(100 \mathrm{mg} / \mathrm{kg}$ body weight) (Pfizer, New York, USA) and $10 \mathrm{mg} / \mathrm{kg}$ xylazine (Xyla-Ject, ADWIA Pharmaceuticals Co, El Obour City, Egypt) $[53,74]$.

Nerve crushing was performed on the right hind limb. The area of incision was shaved, and skin was sterilised with $10 \%$ povidone iodine. A $2-\mathrm{cm}$ incision was then performed along the proximal half of the line between the greater trochanter and the knee joint. To expose the sciatic nerve, a splitting incision was made in the gluteal muscle. The vastus lateralis and biceps femoris muscle were then separated using artery forceps [53].

Nerve crush was performed by applying sustained pressure for $15 \mathrm{~s}$ to the exposed sciatic nerve with artery forceps, at an area $1 \mathrm{~cm}$ proximal to the sciatic nerve division into the tibial and common peroneal nerves. To confirm complete nerve crush injury with intact epineurium, a microprobe was used to elevate the nerve slightly and confirm the appearance of a clear area within the nerve, as shown in Figure 1. Finally, the skin incision was sutured, and rats were kept warm by placing them on a heating pad [53]. Each rat 
received (10 mg/kg) kataflam (Novartis Pharmaceuticals Corporation, East Hanover, New Jersey, USA) via intramuscular injection for pain relief and $(10 \mathrm{mg} / \mathrm{kg})$ flumox (Egyptian Int. Pharmaceutical industries $\mathrm{CO}$ EIPICo, $10^{\text {th }}$ Ramadan City, Egypt) via intramuscular injection to prevent secondary bacterial infection. The local antibiotic Biovitracin spray (Egyptian Company for Advanced Pharmaceuticals, Giza, Egypt) was also applied once daily in spray form (two puffs) to treat local infection. All medications were used for 5 days to facilitate healing. The right hind limb was obtained after animal scarifications and divided into two samples. The first was subjected to histological study and the second was kept in an Eppendorf tube and stored at $-80^{\circ} \mathrm{C}$ until the day of the experiment for biochemical study.

\section{Evaluation methods}

Biochemical study. The frozen sciatic nerve specimens were homogenized in cold $0.9 \% \mathrm{NaCl}$ using glass homogenizer. The homogenates were centrifuged to obtain the supernatant fraction for catalase (CAT), superoxide dismutase (SOD) and malondialdehyde (MDA) determination [70]. Sciatic nerve tissue MDA levels were estimated using Mihara and Uchiyama [43] method based on estimating colour absorbance of complex result from MDA and thiobarbituric acid mixing in an acidic environment at $532 \mathrm{~nm}$ using turnable microplate reader (Molecular Devices, LLC, Sunnyvale, CA, USA). MDA values were expressed as $\mathrm{nmol} / \mathrm{g}$ wet sciatic tissue.

Catalase levels in sciatic nerve tissue (CAT) were measured using Goth's [26] method which depend on measuring the absorbance of yellow coloured complex developed from ammonium molybdate and hydrogen peroxide at $405 \mathrm{~nm}$. Tissue CAT result was expresses as $\mathrm{U} / \mathrm{mg}$ protein. Tissue superoxide dismutase (SOD) was evaluated using Sun et al.'s [60] method. It depends on nitroblue tetrazolium reduction by $\mathrm{O}_{2} \mathrm{~s}$ and measuring the absorbance of the resulting purple formazan molecule at $560 \mathrm{~nm}$ using turnable microplate reader (VERSA max). The final SOD activity was obtained by dividing SOD activity on total protein level and expressed as $\mathrm{U} / \mathrm{mg}$ protein.

Histology. Sciatic nerve specimens were fixed in $10 \%$ formal saline for $24 \mathrm{~h}$ and then processed for paraffinization. The paraffin blocks were cut into slices (of $5 \mu \mathrm{m}$ thickness), and haematoxylin and eosin (H\&E) staining was conducted to determine the general architecture of the sciatic nerve [59].
Histochemistry. Paraffin slices were stained with Masson trichrome (MT) stain to visualise collagen fibres [9].

Immunohistochemistry. The avidin-biotin-peroxidase method was used for immunohistochemical study of neurofilament protein expression. Paraffin-embedded tissue sections were placed on poly-L-lysine coated glass slides, followed by deparaffinization and rehydration in ethyl alcohol. To block endogenous peroxidase activity, the slides were incubated with $3 \%$ hydrogen peroxide in a humidity chamber for 10-15 min, then washed three times with phosphate buffered saline (PBS) for $10 \mathrm{~min}$. Sciatic nerve sections were incubated with primary antibody (polyclonal rabbit anti-neurofilament-200, N4142, Sigma-Aldrich) for $1 \mathrm{~h}$ at $4^{\circ} \mathrm{C}$. Primary antibody was diluted at 1:80 in PBS and kept in a humidity chamber. Sections were first incubated with secondary antibody (1:200, ab97055; Abcam, Cambridge, MA, USA) in PBS for $30 \mathrm{~min}$ at $37^{\circ} \mathrm{C}$ after washing 3 times. Then, section were incubated with the avidin-biotin-peroxidase complex (Universal Elite ABC kit PK-6200; Vectastain, Burlingame, CA, USA) for 30 min followed by rinsing with PBS. Sections were then stained with Vexation diaminobenzidine (DAB) (Kit HK153-5K; Biogenex, San Ramon, CA, USA) for $10 \mathrm{~min}$ to visualise the areas of antibody immunostaining. Finally, the sections were washed with tap water. The sections were counterstained with haematoxylin, dehydrated, cleared, and covered with glass mounted with Canada balsam (C1795, Sigma-Aldrich). The primary antibody was replaced by PBS and served as a negative control. Rat cerebral cortex was used as a positive control. Positive expression of neurofilament protein in the cytoplasm of the nerve fibres was indicated by a brown colour.

Transmission electron microscopy (TEM). Sciatic nerve was cut into small pieces $\left(1 \mathrm{~mm}^{3}\right)$ and kept in $2.5 \%$ gluteraldhyde for $24 \mathrm{~h}$ for fixation. Using an ultra-microtome $0.5-1 \mu \mathrm{m}$-slices were obtained as semithin sections and subjected to toluidine blue staining for analysis via light microscopy. The blocks were trimmed, and some areas were selected for ultrathin sections preparations. The blocks were encapsulated in a copper grid. Uranyl acetate and lead citrate stains were used for ultrathin sections staining, followed by examination using a TEM (Seo-Russia) in the Alexandria Medical Research Institute [9]. 


\section{Quantitative assessment}

Image J software (version K.1.45) was used for measuring the following parameters:

- the number of myelinated axons (nerve fibre number);

- axon cross-sectional area;

- myelin sheath thickness in apparently non-degenerated nerve fibres;

- the percentage of collagen fibres;

- mean percentage of the area of positive neurofilament protein expression.

The quantitative measurements were performed by using a Leica DML B2/11888111 microscope contained Leica DFC450 camera and were evaluated and measured. For each of the chosen groups, five slides were selected from each specimen. Ten non-overlapping fields were picked up for measurement at a $40 \times$ magnification.

\section{Ethical approval}

All relevant institutional, national, and international guidelines related to animal use and care was followed. All methods and strategies were managed according to the guidelines approved by the Animal Research Ethics Committee, Menoufia University, Faculty of Medicine.

\section{Statistical analysis}

Image analysis data were obtained, and their means \pm standard deviation (SD) were calculated and statistically analysed. The different groups were compared using various parameters using one-way analysis of variance (ANOVA) and then post-hoc Bonferroni test to determine statistical significance. Data were considered statistically significant and highly significant at $p<0.05$ and 0.001 , respectively. The results were listed in tables and plotted graphically.

\section{RESULTS}

\section{Histochemical results}

Oxidative enzymes' results in all studied groups are represented in Figure 2A, B. Compared with control group (group I), tissue CAT and SOD activities were significantly decreased $(79.31 \pm 46$ vs. $154.18 \pm 50 \mathrm{U} / \mathrm{mg}$ protein and $86.82 \pm 26.31$ vs. $191.4 \pm 45 \mathrm{U} / \mathrm{mg}$ protein, respectively) while MDA was significantly increased $(6.61 \pm 2.51$ vs. $1.53 \pm 1.1 \mathrm{nmol} / \mathrm{mg}$ protein) in crush group (group II) $(p<0.05)$ as compared to group I. After L-carnitine treatment, tissue CAT and SOD activities were significantly elevated $(139.25 \pm 45$ vs. $79.31 \pm 46$
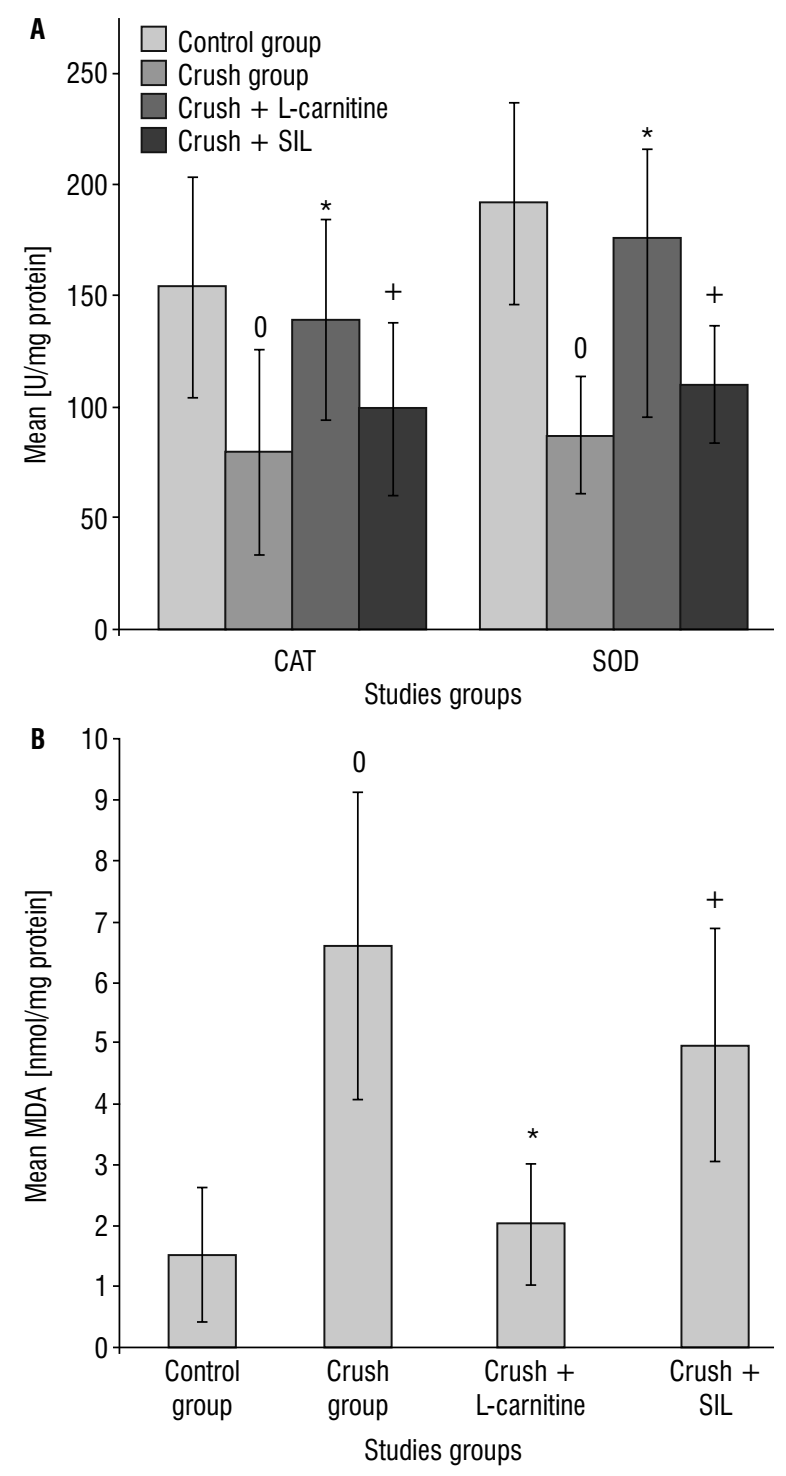

Figure 2. A. A histogram revealing a significant decrease in catalase (CAT) and superoxide dismutase (SOD) level in group II as compared to control group $(0 p<0.05)$ and were significantly elevated in group III as compared to group II $\left({ }^{*} p<0.05\right)$; B. A histogram revealing a significant increase in the malondialdehyde (MDA) level in group II as compared to control group $(0 p<0.05)$ and declined significantly in group III as compared to group II ( $\left.{ }^{*} p<0.05\right)$; SIL - sildenafil $(+p<0.05)$.

and $175.32 \pm 41$ vs. $86.82 \pm 26.31 \mathrm{U} / \mathrm{mg}$ protein, respectively) and MDA level declined significantly (2.06 \pm \pm 0.98 vs. $6.61 \pm 2.51 \mathrm{nmol} / \mathrm{mg}$ protein) as compared to group II ( $p<0.05)$. However, administering SIL also increased CAT and SOD activities (99.54 \pm 39 vs. $79.31 \pm 46$ and $109.62 \pm 27$ vs. $86.82 \pm 26.31 \mathrm{U} / \mathrm{mg}$ protein, respectively) and decreased MDA activity $(4.95 \pm 1.92$ vs. $6.61 \pm 2.51 \mathrm{nmol} / \mathrm{mg}$ protein) as compared to group II but the difference was not statistically significant. 

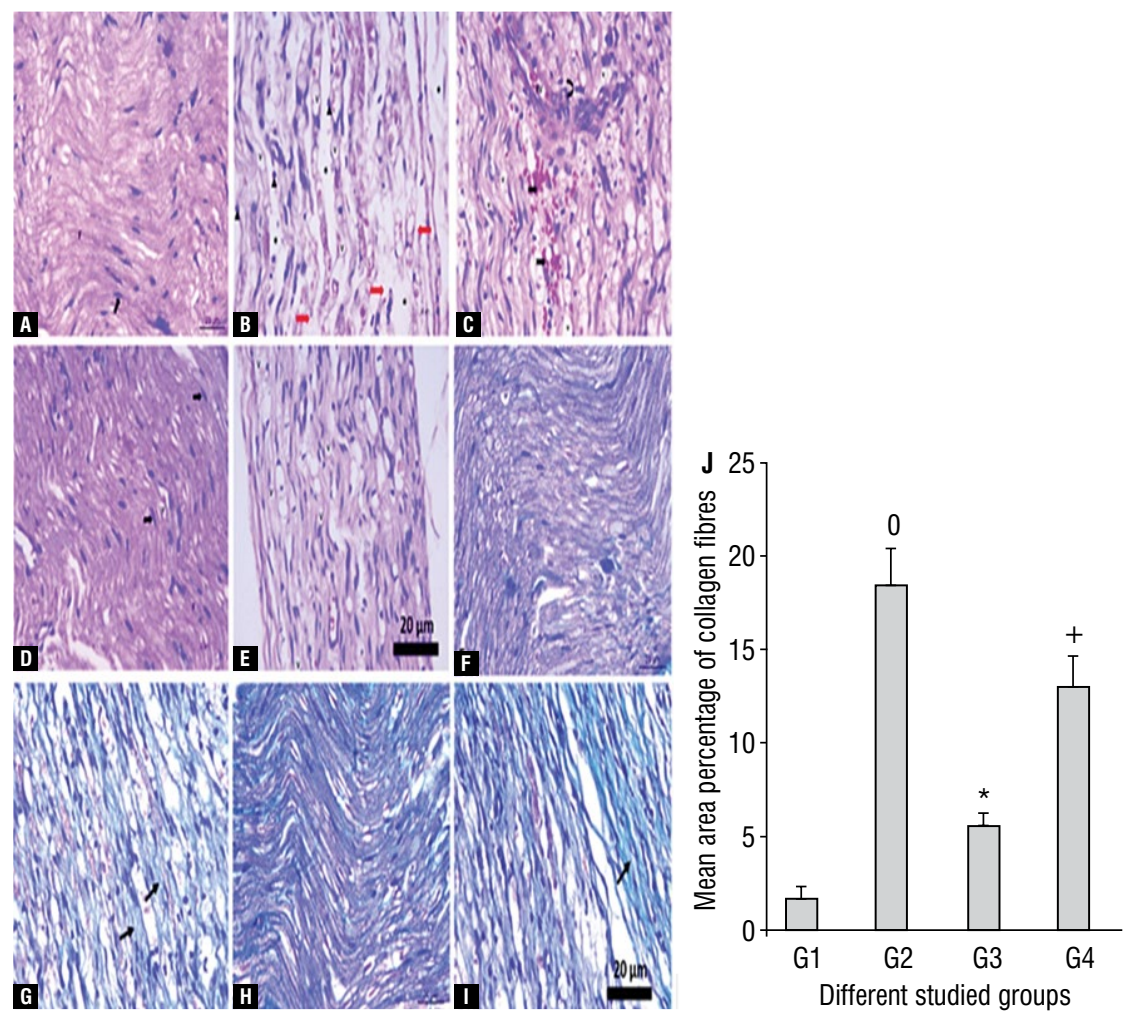

Figure 3. Representative photomicrographs of longitudinal rat sciatic nerve sections from each of the experimental groups; A. Control group I showing myelinated nerve fibres (F), with Schwann cell nuclei (arrow) between the fibres; B. Group II showing discontinuity of most nerve fibres (red arrow), with vacuolated axoplasm (V), some pyknotic nuclei (arrow head), and areas of nerve fibre loss ( ${ }^{*}$ ); C. Group II showing nerve fibres with widespread vacuolations (V), mononuclear cell infiltration (curved arrow), and dilated congested blood vessels (BV) with areas of haemorrhage (notched arrow); D. Group III showing regeneration of most of the nerve fibres (F). Some vacuolation (V) can be seen in the fibres with Schwann cell nuclei (arrow); E. Group IV showing widespread vacuolations (V) (haematoxylin and eosin staining, scale bar $20 \mu \mathrm{m}, 40 \times$ magnification); F. Control group I showing minimal collagen fibres between the nerve axon. A marked increase in collagen fibres was observed in group II (G), a mild increase was observed in group III (H) and a moderate increase was observed in group IV (I) (Masson's trichrome staining, scale bar $20 \mu \mathrm{m}, 40 \times$ magnification); J. Histogram demonstrating a significant increase in the percentage of collagen fibres in both groups II and IV when compared with that in control group I $(0,+p<0.05)$. The percentage of collagen fibres was significantly reduced in group III compared with that in group II ( $\left.{ }^{*} \mathrm{p}<0.05\right)$, and significantly decreased in group III compared to group IV $\left({ }^{*} \mathrm{p}<0.05\right)$.

\section{Histological results}

H\&E-stained longitudinal sections of the different studied groups were examined using light microscopy. In the control group (group I), the nerve fibres were parallel, and were packed together with Schwann cell nuclei between the nerve fibres (Fig. 3A). Sections from the sciatic nerve crush injury group (group II) showed various histological changes, including degenerated and vacuolated axoplasm with areas of nerve fibre loss with pyknotic nuclei. The other sections showed dilated and congested blood vessels with areas of haemorrhage and mononuclear cell infiltration (Fig. 3B, C).

Additionally, in the sections from the L-carnitine-treated sciatic nerve crush injury group (group III), regeneration and some vacuolation was observed in most nerve fibres, with Schwann cell nuclei observed between them (Fig. 3D). Moreover, in the SIL citrate-treat- ed sciatic nerve crush injury group (group IV), most nerve fibres showed widespread vacuolation (Fig. 3E).

The longitudinal sciatic nerve sections from group I control rats showed minimal collagen fibres between nerve axons after MT staining (Fig. 3F). A marked increase in collagen fibres was observed in sections from group II compared to the group I control sections (Figs. 3G). A mild increase in collagen fibres was observed in group III (Fig. $3 \mathrm{H}$ ), while a moderate increase in collagen was observed in group IV (Fig. 31). A statistically significant increase in the percentage of collagen fibres $(p<0.05)$ was observed in both group II and group IV (18.33 \pm 2.51 and $13.0 \pm 1.65$, respectively) compared with that in group I $(1.67 \pm 0.58)$. However, the percentage of collagen fibres significantly decreased in group III when compared with that in group IV (5.50 \pm 0.71 vs. $13.0 \pm 1.65, p<0.05)$. 


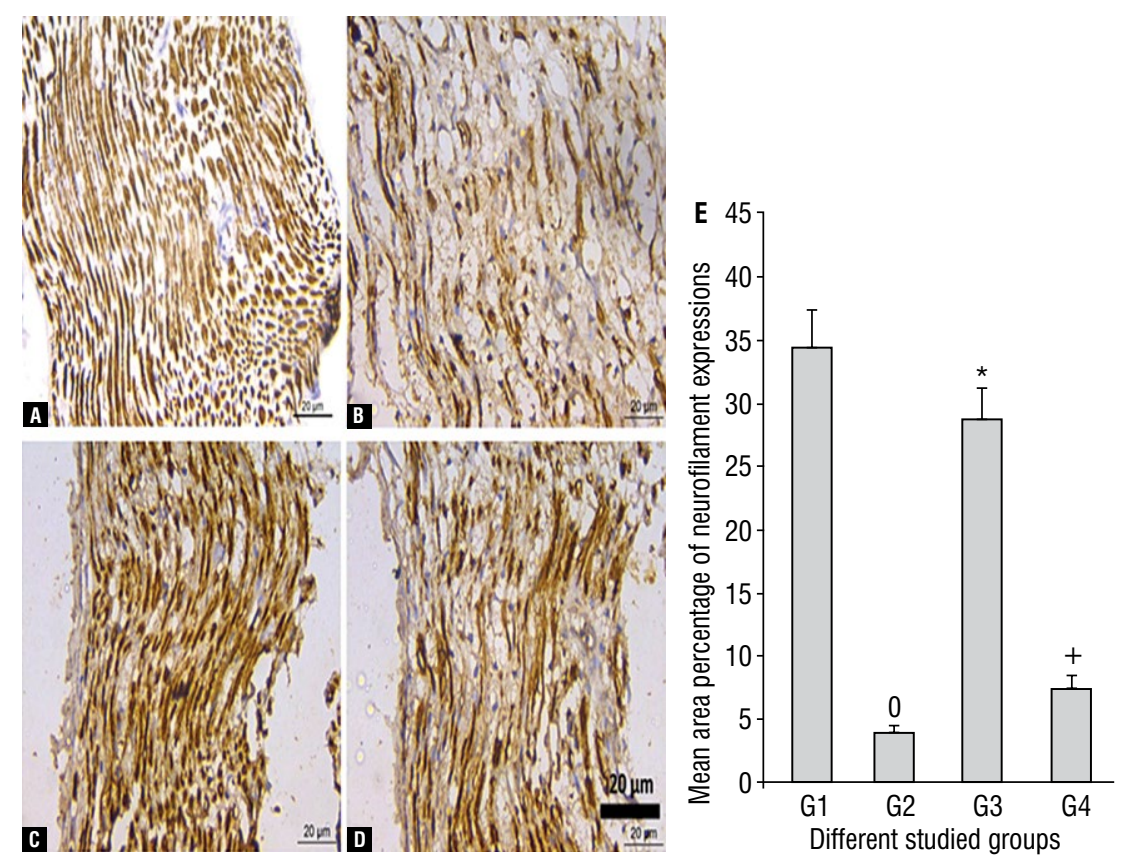

Figure 4. Representative neurofilament immunostaining in rat sciatic nerve sections from the different experimental groups. Immunostaining revealed that neurofilament protein expression was significantly downregulated in groups II and IV compared with the adult control group I $(0,+p<0.05)(\mathbf{A}, \mathbf{B}, \mathbf{D}, \mathbf{E})$, and also in group IV compared with group II $(+p<0.05)(\mathbf{B}, \mathbf{D}, \mathbf{E})$. In contrast, a significant upregulation was observed in group III compared with that in group II ( $\left.{ }^{*} \mathrm{p}<0.05\right)$ (B, C, E) (scale bar $20 \mu \mathrm{m}, 40 \times$ magnification).

Furthermore, the percentage of collagen fibres in group III was reduced compared with that in group II (5.50 \pm 0.71 vs. $18.33 \pm 2.51, \mathrm{p}<0.05$ ) (Fig. 3J).

\section{Immunohistochemical results}

Immunohistochemical staining of the longitudinal sciatic nerve sections revealed that neurofilament protein was significantly downregulated in groups II and IV (3.80 \pm 0.52 and $7.40 \pm 0.89$, respectively) compared with its expression in group I (34.40 \pm $\pm 3.1)(p<0.05)$. Moreover, neurofilament protein was significantly downregulated in group IV compared with that in group II $(p<0.05)$. In contrast, neurofilament protein was significantly upregulated in group III compared with its expression in group II ( $28.60 \pm 2.64$ vs. $3.80 \pm 0.52, p<0.05)$ (Fig. 4 A-E).

\section{Results of toluidine blue staining of semithin sections}

Control group semithin sections stained with toluidine blue demonstrated that part of the nerve bundles were surrounded by perineurium. The myelinated nerve fibres had regular oval or rounded myelin sheaths, and were stained dark blue around the light blue-stained axons. The blood vessels could also be observed (Fig. 5A). Group II showed degenerative changes in the myelin coat, with disintegrated myelin fragments completely covering normal fibre sections areas or compressing the axons. Few nerve fibres with thin myelin could be seen (Fig. 5B). Group III showed restoration of the normal appearance of myelin sheaths compared with the control group (Fig. 5C). Group IV had many myelinated nerve fibres with an irregular myelin sheath, with myelin in-folding and out-folding and degenerated axons (Fig. 5D).

There was a statistically significant reduction in the number of nerve fibres $(p<0.05)$ in both groups II and IV $(2.00 \pm 0.11$ and $4.41 \pm 0.89$, respectively) when compared with that in the control group (28.24 \pm 4.44$)$. However, the number of nerve fibres increased in group III compared with that in group II $(24.29 \pm 1.89$ vs. $2.00 \pm 0.11, p<0.05)$. Moreover, the number of nerve fibres increased in group III when compared with that in group IV $(24.29 \pm 1.89$ vs. $4.41 \pm 0.89, p<0.05$ ) (Fig. 5E).

There was a statistically significant decrease in the mean axon cross-sectional area in groups II and IV (8.68 \pm 1.75 vs. $14.11 \pm 2.89 \mu \mathrm{m}^{2}$, respectively) compared with that in the control group (40.95 \pm $\left.\pm 2.87 \mu \mathrm{m}^{2}, \mathrm{p}<0.05\right)$. However, a significant reduction was observed in the mean axon cross-sectional area in group IV compared with that in group III 

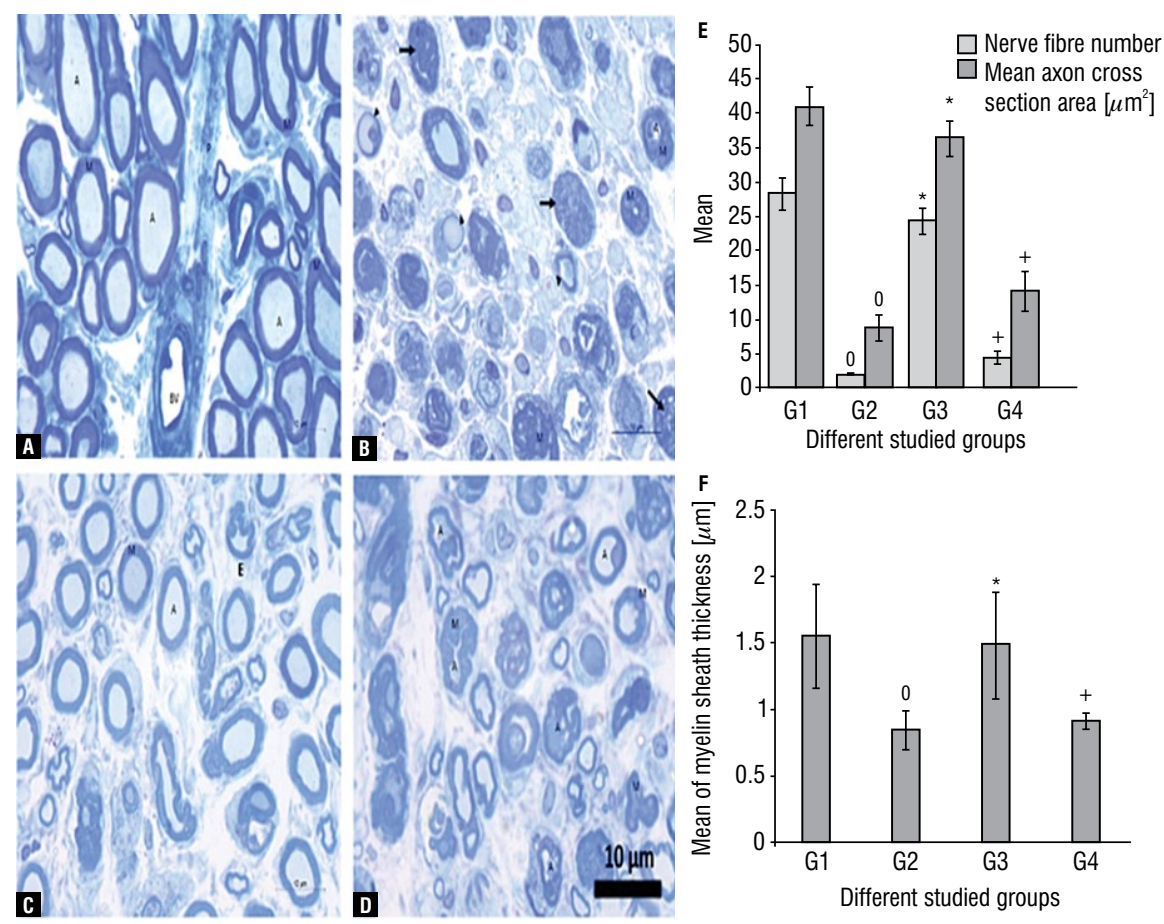

Figure 5. Representative photomicrographs of the stained semithin rat sciatic nerve sections from the different experimental groups; A. Control group I showing bundles of nerve fibres. The myelinated nerve fibres have regular myelin sheaths (M) stained dark blue around the axons (A). The perineurium surrounds the nerve bundles (P), and blood vessels (BV) can be seen; $B$. Degenerative changes of the myelin coat in group II, with disintegrated myelin fragments covering the sections with normal fibres (arrow) or compressing the axons (A). Some have thickened myelin (M) and some nerve fibres have thin myelin (arrowhead); C. Group III showing restoration of the normal appearance of myelin sheaths (M) and axons (A) in most myelinated nerve fibres; D. Group IV showing many myelinated nerve fibres with irregular myelin sheaths (M), with in-folding, out-folding, and degenerated axons (A) (Toluidine blue, scale bar $10 \mu \mathrm{m}, 1000 \times$ magnification); E. Histogram for the number of nerve fibres and the mean axon cross-sectional area showing a significant reduction in the number of nerve fibres and the mean axon cross-sectional area in both group II and group IV compared to that in group I $(0,+p<0.05)$. There were also increased numbers of nerve fibres in group III compared to those in groups II and IV ( $\left.{ }^{*} p<0.05\right)$. The mean axon cross-sectional area was increased in group III compared to group II (* $\mathrm{p}<0.05)$. However, a significant reduction in the mean axon cross-sectional area was observed in group IV compared to that in group III $(+p<0.05)$; $F$. Histogram showing a significant reduction in the mean of myelin sheath thickness in group II and IV compared to that in group I $(0 p<0.05)$. A significant increase in myelin sheath thickness was reported in group III compared to that in group II and IV $\left({ }^{*} p<0.05\right)$. However, a significant reduction in in the mean of myelin sheath thickness was observed in group IV compared to that in group III $(+p<0.05)$.

(14.11 \pm 2.89 vs. $\left.36.26 \pm 2.53 \mu \mathrm{m}^{2}, \mathrm{p}<0.05\right)$. Moreover, there was a significant increase in the mean axon cross-sectional area in group III compared with that in group II $\left(36.26 \pm 2.53\right.$ vs. $8.68 \pm 1.75 \mu \mathrm{m}^{2}$, $\mathrm{p}<0.05$ ) (Fig. 5E).

The thickness of the myelin sheath significantly decreased $(p<0.05)$ in groups II and IV $(0.84 \pm$ $\pm 0.14,0.91 \pm 0.06 \mu \mathrm{m}$ vs. $1.55 \pm 0.39$, respectively) as compared with the control group. Moreover, a highly significant increase $(p<0.05)$ in myelin sheath thickness was reported in group III compared with that in group IV $(1.84 \pm 0.4$ vs. $0.91 \pm 0.06 \mu \mathrm{m}$, respectively). Additionally, there was a highly significant reduction $(p<0.05)$ in myelin sheath thickness in group II compared with that in group III $(0.84 \pm 0.14$ vs. $1.48 \pm 0.40 \mu \mathrm{m}$, respectively) (Fig. 5F).

\section{TEM analysis}

Transmission electron microscopy analysis of the control group showed myelinated axons surrounded by a thick regular myelin sheath. The axoplasm contained mitochondria, neurofilaments, and microtubules. Axons were enclosed by Schwann cell cytoplasm, and the Schwann cell had a large nucleus with peripheral heterochromatin. Groups of unmyelinated nerve fibres were also observed (Fig. 6A).

Transmission electron microscopy examination of group II showed irregular and distorted myelin sheaths. The sheaths did not have a uniform thickness, and some had multiple vacuolations. Other myelin sheaths showed separation in the myelin sheath lamellae. Retracted degenerated myelinated axons with small vacuolation were observed in the 

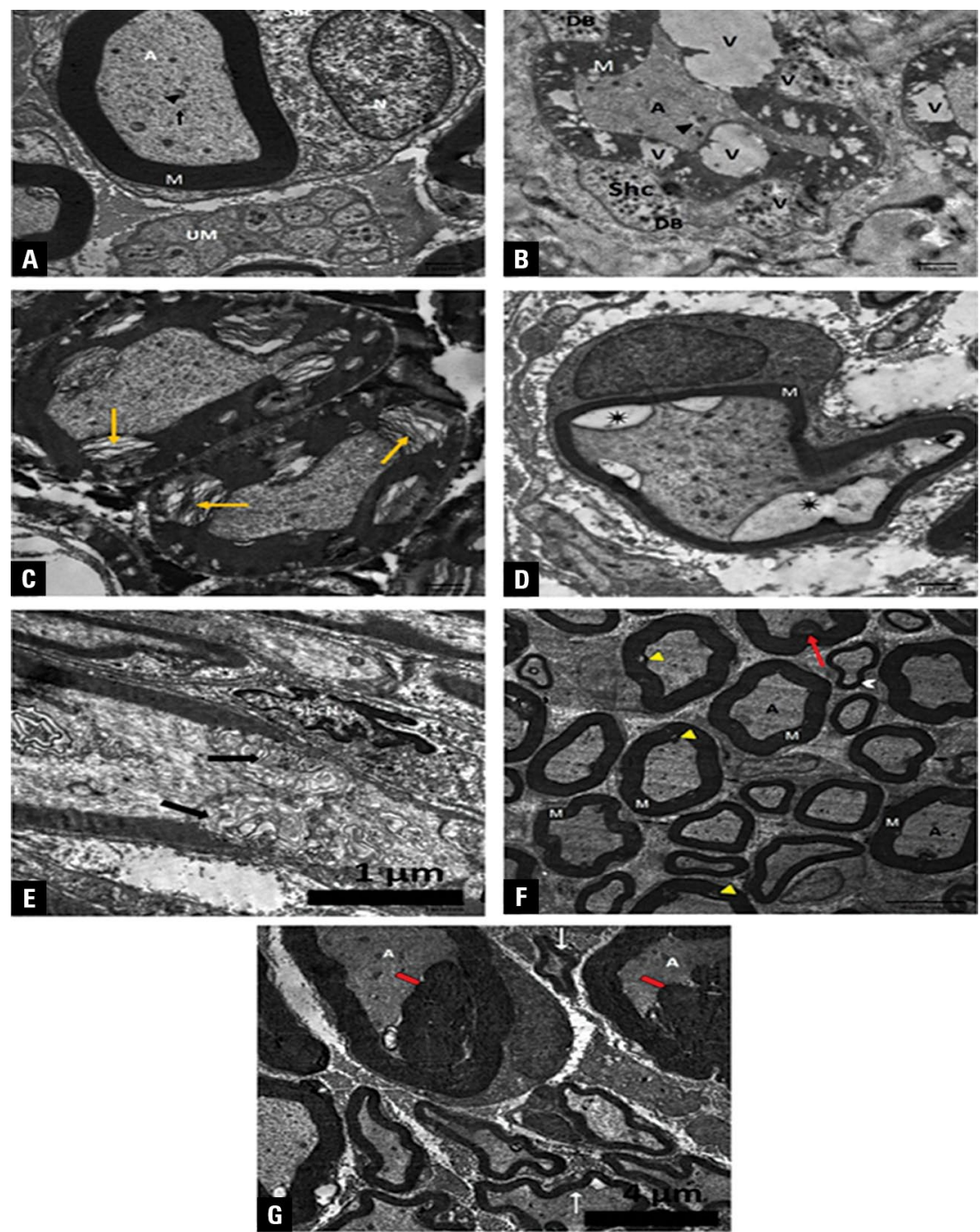

Figure 6. Representative electron micrographs of rat sciatic nerve sections from the different experimental groups; A. Cross-section of control group showing myelinated axons (A) ensheathed with a myelin sheath (M) of uniform thickness. The electron-dense dots present in the axons are neurotubules, neurofilaments (arrow), and mitochondria (arrow head). Schwann cells (Shc) have large nuclei (N) and enclose the myelinated nerve fibres. Unmyelinated nerve fibres are indicated (UM); B. Cross-section of the group II showing an irregular myelin sheath (M) with multiple vacuolations (V). These are enclosed by Schwann cells (Shc), which have vacuolated (V) cytoplasm and dense bodies (DB). We observed a compressed axon (A) with a small vacuolation (arrow head); C. Cross-section of the group II showing separation in the myelin sheath lamellae (yellow arrow); D. Cross-section of the group II with a thin and irregular myelin sheath (M) and axon retraction $\left({ }^{*}\right)$; E. Longitudinal section of group II showing distortion of the myelin sheath (arrow) and an irregular indented Schwan cell nucleus (ShcN) with peripheral chromatin condensation; F. Cross-section from group III, showing that myelinated nerves appear nearly normal with a regular compact myelin sheath (M) and homogenous axoplasm (A). Some of the myelin sheaths have either splitting (yellow head arrow) or in-folding (red arrow), while others are thin and irregular (chevron arrow); G. Cross-section from group IV, showing an irregular myelin sheath (arrow) with focal thickening in some nerve fibres (red arrow) compressing the axons (A). (A-E, 17500 $\times$ magnification) (F, G, 5000× magnification).

axoplasm (Fig. 6B-E). The Schwann cell nucleus was irregular and indented with peripheral chromatin condensation. In another section, the Schwann cell cytoplasm had multiple vacuolations and dense bodies (Fig. 6E, B).

Group III mostly demonstrated normal myelinated nerves with a regular compact myelin sheath and homogenous axoplasm. However, some nerve fibres still had splitting in the myelin sheath (Fig. 6F). Group IV had some nerve fibres with irregular myelin sheaths, with focal thickening compressing the axons (Fig. 6G)

\section{DISCUSSION}

Peripheral nervous system injuries are increasing in frequency, and pose a health hazard. Such injuries mostly affect young adults, resulting from traffic acci- 
dents, falls, and surgery [42]. These injuries may lead to lifelong debilitating disability, potentially resulting in loss of organ functions [76]. Feng and Yuan [21] concluded that drugs can be a reliable method for obtaining acceptable functional recovery in crush injury, but that surgical repair is a more precise option for transection injury.

In a peripheral nerve crush injury, the mechanism of injury is unclear, as some nerve integrity is maintained. Emel et al. [19] have demonstrated that the possible mechanism of crush injury is due to mechanical compression, followed by oedema and ischaemia of the crushed nerve fibres. Moreover, enhanced arachidonic acid metabolism and both intracellular and extracellular endoperoxide accumulations occur at the lesion site as sequalae of morphological changes and deficient oxygen supply [73]. Zhang and Chopp [74] concluded that neurorepair processes (angiogenesis and neurogenesis) are activated in adults after the occurrence of various pathological conditions.

Sciatic nerve crush injury results in vasa nervosa damage and impairment of nerve blood flow if persistent compressive ischaemia lasts for long period [45]. The pathology of crush injury in sciatic nerve may be due to various factors such as endogenous chemical mediators' accumulation, apoptosis, free radical generation and ischaemia [59]. Oxidative stress gives rise to cellular damage with activating apoptosis. Free oxygen radicles (ROS) are the main source of lipid peroxidation (LPO) and induce oxidative stress by modulating antioxidant activities [52]. Various antioxidant enzymes as CAT, SOD and glutathione peroxidase (GSH) can be involved in detoxification of ROS. CAT and SOD are capable of scavenging peroxide and superoxide anions [12]. Therefore, their elevated level in tissue pointed to raised antioxidant activity [58]. Hence, during cell injury, there is a reduction in antioxidant enzymes activity such as SOD, CAT and GSH [62]. On the other hand, MDA and myeloperoxidase activity was reported to increase due to inflammatory reaction associated with tissue injury leading to direct membrane function impairment and indirect cellular component damage [71].

In the current study tissue CAT and SOD activities were significantly decreased in crushed group as compared to control group $(p<0.05)$ while MDA was significantly increased $(p<0.05)$. Our findings were in line with Kocaoglu et al. [38] who reported same findings. They explained that nerve compression induced blood brain barrier disruption and nerve oedema with a decrease in peripheral nerve oxygen supply and morphological changes. The previous findings enhance arachidonic acid metabolism and permit unstable endoperoxides accumulation both extracellular and intracellular. Moreover, reperfusion after nerve compression causes free radical formation similar to ischaemia-reperfusion injury [73]. Nervous system injuries stimulate glutamate production, glutamate receptor activation and calcium ion accumulation with subsequent induction of ROS, hydrogen peroxide, and superoxide anion formation. Lipid peroxidation cascades are initiated by oxidative stress leading to cell membrane damage during the initial period after injury [18].

Light microscopic examination of the H\&E sections from the specimen of nerve crush injury group showed degenerated and vacuolated axoplasm, with areas of nerve fibre loss and pyknotic nuclei. Other sections showed dilated and congested blood vessels with areas of haemorrhage and mononuclear cell infiltration. These findings were in accordance with those obtained by some researches $[4,40,61]$. These findings were supported by a significant reduction in the number of sciatic nerve fibres $(p<0.05)$ in the sciatic nerve crush group compared to that in control group. This was reflected by the weak anti-neurofilament antibody expression observed in the crush group. Tomassoni et al. [63] reported the apparent loss of both myelinated and unmyelinated nerve fibres after nerve ligation. Moreover, Di Cesare Mannelli et al. [15] determined that more significant axonal degeneration and nerve trunk apoptosis, along with Schewann cells DNA fragmentation in the nuclei, were reported in the distal end of the nerve.

In the current study, MT staining revealed a significant increase in the perineurial and endoneurial collagen fibres in group II compared to those in group III and the control group $(p<0.05)$. This can be attributed to fibrin deposition as a consequence of sciatic nerve injury, resulting in enhanced nerve damage, alteration of the composition of the extracellular matrix and the suppression of Schwann cell migration [16]. However, an inflammatory reaction with proinflammatory cytokines occurs due to fibrin deposition and macrophage accumulation. This may induce tissue injury, but its main role lies in mechanisms involved in tissue regeneration [49]. Moreover, other studies involving sciatic nerve crush injury have observed an increased number of endoneurial fibroblasts and an accumulation of connective tissue in the interfibre endoneurium [35]. 
In this manuscript, we observed misexpression and weak neurofilament expression in group II; there was strong neurofilament expression in the nerve fibres in group III. Additionally, the mean percentage of the area of neurofilament expression increased in a significant manner $(p<0.05)$ in the control group compared to groups II and VI. Our results are in accordance with those obtained by Song et al. [58] who observed that a decrease in positive neurofilament expression in the nervous system microtubules was correlated with diabetes and various nerve injuries. This results from a disturbance in the synthesis and transport of neuronal substances, and therefore, the irregular activity in the nervous system.

The immunohistochemical findings from our study were supported by a significant increase in the number of sciatic nerve fibres $(p<0.05)$ in group III compared to that in group II. These immunohistochemical findings are in line with those obtained by Khabiri et al. [33] who reported that olfactory ensheathing cells transplantation accelerates nerve axon myelination and regeneration following crush nerve injury. Omura et al. [48] concluded that neurofilament expression in sciatic nerve axons was correlated with early signs of nerve regeneration.

In the present study, TEM examination of the nerve crushed group showed irregular and distorted myelin sheaths with lamellar separation and degenerated myelinated axons. However, the Schwann cell nucleus was irregular and indented with peripheral chromatin condensation, while multiple vacuolations and dense bodies were reported in its cytoplasm. These results are consistent with previous research demonstrating myelin sheath degeneration and splitting [1, 2]. Furthermore, Tamaddonfard et al. [61] suggested that Schwann cells accumulation and the attraction of macrophages to the nerve injury site can assist scavengers of degenerated nerve axons and myelin sheath fragmentation to enhance the initiation of nerve regeneration. Moreover, previous studies have suggested that the regeneration process is influenced by inflammatory changes and oxidative stress at the injury site and the distal nerve $[28,56]$.

Yuan and Feng [72] demonstrated that Wallerian degeneration can occur after sciatic nerve crush injury, which involves nerve axon degeneration, Schwann cell accumulation, myelin sheath disintegration and macrophage infiltration. Moreover, Schwann cells and macrophages play a major role in the secretion of various cytokines and a variety of inflammatory medi- ators, such as IL- $1 \beta$, TNF- $\alpha$ and interferon, all of which regulate Wallerian degeneration $[35,57]$. Additionally, damaged tissue proximal to the injured area may inhibit axonal extension and impair the healing process. Wallerian degeneration may assist macrophages and white blood cells accumulation to remove the damaged myelin sheath and injured axons. Furthermore, accelerated Schwann cell division and differentiations plays a major role in axon renewal $[41,66,75]$.

L-carnitine is a potent antioxidant with neuroprotective potential and can suppress oxidative damage in neurodegenerative diseases such as Parkinson's and Alzheimer's disease [3, 27]. It is considered as an exogenous neurotrophic factor, decreasing neuronal loss after nerve injury and improving neuronal regeneration [67]. Collectively, we explored the possible ameliorative effects of L-carnitine administration on sciatic nerve crush damage. L-carnitine administration improved the antioxidant status as proved in group III. Administration of L-carnitine after crush nerve injury improved all biochemical parameters as tissue CAT and SOD activities were significantly elevated and MDA level declined significantly $(p<0.05)$ as compared to group II. It also reduces the damage to the axon and myelin sheath, with a near-normal structure observed in the nerve fibres. Our results were in accordance with findings reported by Avsar et al. [6] who studied the alleviating effect of L-carnitine on sciatic nerve crush injury in rats. It was found that L-carnitine had an effect on the recovery of sciatic nerve function as well as enhancing nerve regeneration and suppressing injury-induced degeneration in the nerve axon and its myelin sheath. Wilson et al. [68] and Babicova et al. [7] explained that L-carnitine blocked the cell death pathway at the mitochondrial level by limiting reactive oxygen species synthesis in addition to reducing the nitric oxide and nitric oxide synthase levels.

Sildenafil is a PDE-5 inhibitor with neuroprotective effect, which is initiated by stimulating neurotrophic factors encountered in neuronal regeneration and survival [29]. In this manuscript, SIL administration in group IV led to a mild improvement in the histopathological findings and biochemical parameters as proved by increased CAT and SOD activities and decreased MDA activity as compared to group II but the difference was not statistically significant. These results were in line with those obtained by Vakharia et al. [65] who studied the neuroprotective properties of SIL on facial nerve functional recovery following 
nerve crush injury. The study concluded that SIL administration following facial nerve crush injury had only a mild transient effect on the functional recovery of the facial nerve, despite its neuroprotective effect in previous studies. On the other hand, Garcia et al. [24] found that SIL could ameliorate oxidative and inflammatory stress on pelvic ganglion neurons after inducing damage to bilateral cavernosal nerve through compensatory elevated antioxidant enzymes. These findings were proved by an increase in NADPH complex expression such as p22-phox and toxol which represent the main source of ROS formation. It indicates higher ability for superoxide production. It may also induce anti-inflammatory feedback. This was thought to occur by regulating inflammatory cytokine expression by preventing leukocyte accumulation and migration near the neuronal lesion. Moreover, Jeong et al. [31] studied the effect of SIL on the kidneys of streptozotocin-diabetic rats and reported diminished oxidative stress and reduced pro-inflammatory cytokine expression.

Quantitative morphometric study demonstrated a significant increase in the thickness of the myelin sheath, the number of nerve fibres, and the axon cross-sectional area in L-carnitine-treated group. These findings were in agreement with those obtained by Avsar et al. [6] who concluded that L-carnitine had an excellent ability to prevent nerve function loss following nerve injury, accelerate nerve degeneration, and ameliorate axon and myelin sheath degeneration. On contrary to insignificant increase in the previous parameters in the group treated with SIL.

According to the histopathologic, immunohistochemical, and histo-morphometric findings, L-carnitine had an alleviating effect on nerve crush injury lesions, and this effect was greater than that observed by SIL administration. This is suggestive of the more potent antioxidant and anti-inflammatory effect of L-carnitine with respect to nerve injuries.

\section{CONCLUSIONS}

Nerve crush injury can result in serious debilitating effects which can be partially relieved by administering substances such as nutrients and drugs. In this study, by means of histopathology, electron microscopy, and morphometric studies, it was demonstrated that these effects may be alleviated by L-carnitine administration and minimally ameliorated by SIL uptake. It provides a new scope to the neuroregenerative effect of L-carnitine on nerve compression.

\section{Acknowledgements}

Thanks to Elsiver for precise Language Editing Services.

Work was conducted in: Faculty of Medicine, Menoufia University, Egypt; Alexandria Medical Research Institute, Alexandria, Egypt.

\section{Conflict of interest: None declared}

\section{REFERENCES}

1. Abd-El-Hafez A. Effect of leflunomide on sciatic nerve of AbdEl-Hafez A. Effect of leflunomide on sciatic nerve of adult albino rats. Egypt J Histol. 2014; 37(2): 258-268, doi: 10.1097/01. ehx.0000446588.04196.df.

2. Abd EIS, Raafat M, Shokry Y. ogical study on the role of bone marrow derived mesenchymal stem cells on the sciatic nerve and the gastrocnemius muscle in a model of sciatic nerve crush injury in albino rats. Egypt J Histol. 2015; 38(3): 438-451, doi: 10.1097/01. EHX.0000470653.672 31.07.

3. Abdul HM, Butterfield DA. Involvement of PI3K/PKG/ERK1/2 signaling pathways in cortical neurons to trigger protection by cotreatment of acetyl-L-carnitine and alpha-lipoic acid against HNE-mediated oxidative stress and neurotoxicity: implications for Alzheimer's disease. Free Radic Biol Med. 2007; 42(3): 371-384, doi: 10.1016/j.freeradbiomed.2006.11.006, indexed in Pubmed: 17210450.

4. Alqalla M, Tawfik M, Grawish M. The effects of low-level laser treatment on recovery of nerve conduction after sciatic nerve compression injury (experimental study). J Am Sci. 2016; 12(9): 5-11, doi: 10.7537/marsjas120916.02.

5. American Heart Association. Viagra Helps Men with Heart Failure. Science Daily. http://www.sciencedaily.com/ releases/2002/ 08/0208070 64924.htm (2002; 7 August).

6. Avsar UZ, Avsar U, Aydin A, et al. L-carnitine alleviates sciatic nerve crush injury in rats: functional and electron microscopy assessments. Neural Regen Res. 2014; 9(10): 1020-1024, doi: 10.4103/1673-5374.133163, indexed in Pubmed: 25206754.

7. Babicová $A$, Havlínová $Z$, Hroch $M$, et al. In vivo study of radioprotective effect of NO-synthase inhibitors and acetyl-L-carnitine. Physiol Res. 2013; 62(6): 701-710, doi: 10.33549/ physiolres.932541, indexed in Pubmed: 23869893.

8. Bagdatoglu C, Saray A, Surucu HS, et al. Effect of trapidil in ischemia/reperfusion injury of peripheral nerves. Neurosurgery. 2002; 51(1): 212-9; discussion 219, doi: 10.1097/00006123200207000-00031, indexed in Pubmed: 12182420.

9. Bancroft JD, Gamble M. Theory and practice of histological techniques, 6 th ed. Churchill Livingstone Elsevier, Philadelphia 2008: 126, 150, 440.

10. Burnett $M$, Zager E. Pathophysiology of peripheral nerve injury: a brief review. Neurosurgical Focus. 2004; 16(5): 1-7, doi: 10.3171/foc.2004.16.5.2.

11. Cavallini G, Caracciolo S, Vitali G, et al. Carnitine versus androgen administration in the treatment of sexual dysfunction, depressed mood, and fatigue associated with male aging. Urology. 2004; 63(4): 641-646, doi: 10.1016/j.urology.2003.11.009, indexed in Pubmed: 15072869.

12. Cetinkaya A, Bulbuloglu E, Kantarceken B, et al. Effects of L-carnitine on oxidant/antioxidant status in acetic acid-induced colitis. Dig Dis Sci. 2006; 51(3): 488-494, doi: 10.1007/s10620006-3160-9, indexed in Pubmed: 16614957.

13. Chen CJ, Ou YC, Liao SL, et al. Transplantation of bone marrow stromal cells for peripheral nerve repair. Exp Neurol. 2007; 204(1): 443-453, doi: 10.1016/j.expneurol.2006.12.004, indexed in Pubmed: 17222827. 
14. Chiechio S, Copani A, Gereau RW, et al. Acetyl-L-carnitine in neuropathic pain: experimental data. CNS Drugs. 2007; 21 Suppl 1: 31-8; discussion 45, doi: 10.2165/00023210-20072100100005, indexed in Pubmed: 17696591.

15. Di Cesare Mannelli L, Ghelardini C, Calvani M, et al. Neuroprotective effects of acetyl-L-carnitine on neuropathic pain and apoptosis: a role for the nicotinic receptor. J Neurosci Res. 2009; 87(1): 200-207, doi: 10.1002/jnr.21815, indexed in Pubmed: 18709658.

16. El-Azab NE, El-Mahalaway A, Mostafa O, et al. Histological and immunohistochemical study of the potential therapeutic impacts of bone marrow mesenchymal stem cells and exosomes for sciatic nerve crush injury model in rats. J Histotechnol. 2018; 41(4): 160-176, doi: 10.1080/01478885.2018.1505205.

17. El Desoky ES, Fouad IA. Pharmacological evidence for the role of nitric oxide-CGMP in antinociception. J Appl Res. 2005; 5: 451-459.

18. Emmez H, Yildirim Z, Kale A, et al. Anti-apoptotic and neuroprotective effects of $\alpha$-lipoic acid on spinal cord ischemia-reperfusion injury in rabbits. Acta Neurochir (Wien). 2010; 152(9): 1591-600; discussion 1600, doi: 10.1007/s00701-010-0703-9, indexed in Pubmed: 20535507.

19. Emel E, Ergün SS, Kotan D, et al. Effects of insulin-like growth factor-I and platelet-rich plasma on sciatic nerve crush injury in a rat model. J Neurosurg. 2011; 114(2): 522-528, doi: 10.3171/2010.9.JNS091928, indexed in Pubmed: 21029038.

20. Eto $M$, Sumi $H$, Fujimura $H$, et al. Pioglitazone promotes peripheral nerve remyelination after crush injury through CD36 upregulation. J Peripher Nerv Syst. 2008; 13(3): 242-248, doi: 10.1111/j.1529-8027.2008.00183.x, indexed in Pubmed: 18844791

21. Feng $X$, Yuan W. Dexamethasone enhanced functional recovery after sciatic nerve crush injury in rats. Biomed Res Int. 2015; 2015: 627923, doi: 10.1155/2015/627923, indexed in Pubmed: 25839037

22. Galeotti N, Bartolini A, Calvani M, et al. Acetyl-L-carnitine requires phospholipase C-IP3 pathway activation to induce antinociception. Neuropharmacology. 2004; 47(2): 286-294, doi: 10.1016/j.neuropharm.2004.03.016, indexed in Pubmed: 15223307.

23. Gao Y, Weng $C$, Wang $X$. Changes in nerve microcirculation following peripheral nerve compression. Neural Regen Res. 2013; 8(11): 1041-1047, doi: 10.3969/j.issn.1673-5374.2013.11.010, indexed in Pubmed: 25206398.

24. Garcia LA, Hlaing SuM, Gutierrez RA, et al. Sildenafil attenuates inflammation and oxidative stress in pelvic ganglia neurons after bilateral cavernosal nerve damage. Int J Mol Sci. 2014; 15(10): 17204-17220, doi: 10.3390/ijms151017204, indexed in Pubmed: 25264738.

25. Gibson A. Phosphodiesterase 5 inhibitors and nitrergic transmission - from zaprinast to sildenafil. Eur J Pharmacol. 2001; 411(1-2): 1-10, doi: 10.1016/s0014-2999(00)00824-4.

26. Góth L. A simple method for determination of serum catalase activity and revision of reference range. Clinica Chimica Acta. 1991; 196(2-3): 143-151, doi: 10.1016/0009-8981(91)90067-m.

27. Gülçin I. Antioxidant and antiradical activities of L-carnitine. Life Sci. 2006; 78(8): 803-811, doi: 10.1016/j.Ifs.2005.05.103, indexed in Pubmed: 16253281

28. Helvacioglu F, Kandemir E, Karabacak B, et al. Effect of creatine on rat sciatic nerve injury: a comparative ultrastructural study. Turk Neurosurg. 2016; 28(1): 128-136, doi: 10.5137/1019-5149. JTN.18806-16.0, indexed in Pubmed: 27858383.

29. Hlaing SuM, Garcia LA, Kovanecz I, et al. Sildenafil promotes neuroprotection of the pelvic ganglia neurones after bilateral cavernosal nerve resection in the rat. BJU Int. 2013; 111(1): 159-170, doi: 10.1111/j.1464-410X.2012.11278.x, indexed in Pubmed: 22672418.

30. Duarte I, Lorenzetti BB, Ferreira SH. Peripheral analgesia and ac- tivation of the nitric oxide-cyclic GMP pathway. Eur J Pharmacol. 1990; 186(2-3): 289-293, doi: 10.1016/0014-2999(90)90446-d.

31. Jeong $\mathrm{KH}$, Lee TW, Ihm CG, et al. Effects of sildenafil on oxidative and inflammatory injuries of the kidney in streptozotocin-induced diabetic rats. Am J Nephrol. 2009; 29(3): 274-282, doi: 10.1159/000158635, indexed in Pubmed: 18812693.

32. Karsidag S, Akcal A, Sahin S, et al. Neurophysiological and morphological responses to treatment with acetyl-L-carnitine in a sciatic nerve injury model: preliminary data. J Hand Surg Eur Vol. 2012; 37(6): 529-536, doi: 10.1177/1753193411426969, indexed in Pubmed: 22080531.

33. Kabiri M, Oraee-Yazdani S, Shafiee A, et al. Neuroregenerative effects of olfactory ensheathing cells transplanted in a multi-layered conductive nanofibrous conduit in peripheral nerve repair in rats. J Biomed Sci. 2015; 22(1), doi: 10.1186/ s12929-015-0144-0.

34. Khan A, Faruqi N, Ansari M. Effects of hydrocortisone on the sciatic nerve crush injury in adult rat: a light microscopic study. Curr Neurobiol. 2014; 5(1, 2): 11-16.

35. Khan A, Ajmal M, Faizal M. Effects of vitamin C on regeneration of sciatic nerve crush injury in adult rats: a light microscopic study. JIARM. 2015; 3(8): 68-77.

36. Kidd PM. Alzheimer's disease, amnestic mild cognitive impairment, and age-associated memory impairment: current understanding and progress toward integrative prevention. Altern Med Rev. 2008; 13(2): 85-115, indexed in Pubmed: 18590347.

37. Kim TH, Yoon SJ, Lee WC, et al. Protective effect of GCSB-5, an herbal preparation, against peripheral nerve injury in rats. J Ethnopharmacol. 2011; 136(2): 297-304, doi: 10.1016/j. jep.2011.04.037, indexed in Pubmed: 21569830.

38. Kocaoğlu S, Aktaş Ö, Zengi O, et al. Effects of alpha lipoic acid on motor function and antioxidant enzyme activity of nerve tissue after sciatic nerve crush injury in rats. Turk Neurosurg. 2017 [Epub ahead of print], doi: 10.5137/1019-5149.JTN.18585-16.1, indexed in Pubmed: 29044452.

39. Korkmaz MF, Parlakpınar H, Ceylan MF, et al. The effect of sildenafil on recuperation from sciatic nerve injury in rats. Balkan Med J. 2016; 33(2): 204-211, doi: 10.5152/balkanmedj.2016.14701, indexed in Pubmed: 27403391.

40. Li HF, Wang YR, Huo HP, et al. Neuroprotective effects of ultrasound-guided nerve growth factor injections after sciatic nerve injury. Neural Regen Res. 2015; 10(11): 1846-1855, doi: 10.4103/1673-5374.170315, indexed in Pubmed: 26807123.

41. Li R, Wu J, Lin Z, et al. Single injection of a novel nerve growth factor coacervate improves structural and functional regeneration after sciatic nerve injury in adult rats. Exp Neurol. 2017; 288: 1-10, doi: 10.1016/j.expneurol.2016.10.015, indexed in Pubmed: 27983992.

42. Marconi S, Castiglione G, Turano E, et al. Human adipose-derived mesenchymal stem cells systemically injected promote peripheral nerve regeneration in the mouse model of sciatic crush. Tissue Eng Part A. 2012; 18(11-12): 1264-1272, doi: 10.1089/ten.TEA.2011.0491, indexed in Pubmed: 22332955.

43. Mihara M, Uchiyama M. Determination of malonaldehyde precursor in tissues by thiobarbituric acid test. Anal Biochem. 1978; 86(1): 271-278, doi: 10.1016/0003-2697(78)90342-1, indexed in Pubmed: 655387.

44. Mixcoatl-Zecuatl T, Aguirre-Bañuelos P, Granados-Soto V. Sildenafil produces antinociception and increases morphine antinociception in the formalin test. Eur J Pharmacol. 2000; 400(1): 81-87, doi: 10.1016/s0014-2999(00)00361-7, indexed in Pubmed: 10913588.

45. Morani A, Bodhankar S. Neuroprotective effect of vitamin E acetate in models of mononeuropathy in rats. Neuroanatomy. 2008; 7: 33-37.

46. Namazi H, Emami MJ, Dehghani Nazhvani F, et al. Simvastatin vs. L-Carnitine: An experimental study on optimizing nerve repair. 
Turk Neurosurg. 2019 [Epub ahead of print], doi: 10.5137/10195149.JTN.25821-19.2, indexed in Pubmed: 31099885.

47. Navarro X, Vivó M, Valero-Cabré A. Neural plasticity after peripheral nerve injury and regeneration. Prog Neurobiol. 2007; 82(4): 163-201, doi: 10.1016/j.pneurobio.2007.06.005, indexed in Pubmed: 17643733.

48. Omura K, Ohbayashi M, Sano M, et al. The recovery of bloodnerve barrier in crush nerve injury--a quantitative analysis utilizing immunohistochemistry. Brain Res. 2004; 1001(1-2): 13-21, doi: 10.1016/j.brainres.2003.10.067, indexed in Pubmed: 14972650.

49. Pan HC, Yang DY, Ho SP, et al. Escalated regeneration in sciatic nerve crush injury by the combined therapy of human amniotic fluid mesenchymal stem cells and fermented soybean extracts, Natto. J Biomed Sci. 2009; 16: 75, doi: 10.1186/1423-0127-16-75, indexed in Pubmed: 19698158.

50. Patil CS, Singh VP, Kulkarni SK. Modulatory effect of sildenafil in diabetes and electroconvulsive shock-induced cognitive dysfunction in rats. Pharmacol Rep. 2006; 58(3): 373-380, indexed in Pubmed: 16845211.

51. Pettegrew JW, Levine J, McClure RJ. Acetyl-L-carnitine physical-chemical, metabolic, and therapeutic properties: relevance for its mode of action in Alzheimer's disease and geriatric depression. Mol Psychiatry. 2000; 5(6): 616-632, doi: 10.1038/ sj.mp.4000805, indexed in Pubmed: 11126392.

52. Ragy MM. Effect of exposure and withdrawal of 900-MHz-electromagnetic waves on brain, kidney and liver oxidative stress and some biochemical parameters in male rats. Electromagn Biol Med. 2015; 34(4): 279-284, doi: 10.3109/15368378.2014.906446, indexed in Pubmed: 24712749.

53. Ramli D, Aziz I, Mohamad M, et al. The changes in rats with sciatic nerve crush injury supplemented with evening primrose oil: behavioural, morphologic, and morphometric analysis. Evid Based Complement Alternat Med. 2017; 2017: 3476407, doi: 10.1155/2017/3476407, indexed in Pubmed: 28620418.

54. Roglio I, Bianchi R, Gotti S, et al. Neuroprotective effects of dihydroprogesteroone in an experimental model of nerve crush injury. Neuroscience. 2008; 155: 673-685.

55. Rump TJ, Abdul Muneer PM, Szlachetka AM, et al. Acetyl-L-carnitine protects neuronal function from alcohol-induced oxidative damage in the brain. Free Radic Biol Med. 2010; 49(10): 1494-1504, doi: 10.1016/j.freeradbiomed.2010.08.011, indexed in Pubmed: 20708681.

56. Senoglu M, Nacitarhan V, Kurutas EB, et al. Intraperitoneal Alpha-Lipoic Acid to prevent neural damage after crush injury to the rat sciatic nerve. J Brachial Plex Peripher Nerve Inj. 2009; 4: 22, doi: 10.1186/1749-7221-4-22, indexed in Pubmed: 19939272.

57. Smith $D$, Tweed $C$, Fernyhough $P$, et al. Nuclear factor-kappaB activation in axons and Schwann cells in experimental sciatic nerve injury and its role in modulating axon regeneration: studies with etanercept. J Neuropathol Exp Neurol. 2009; 68(6): 691-700, doi: 10.1097/NEN.0b013e3181a7c14e, indexed in Pubmed: 19458540.

58. Song C, Yang Z, Zhong M, et al. Sericin protects against diabetes-induced injuries in sciatic nerve and related nerve cells. Neural Regen Res. 2013; 8(6): 506-513, doi: 10.3969/j. issn.1673-5374.2013.06.003, indexed in Pubmed: 25206693.

59. Stevens A, Wilson IG. The haematoxylin and eosin. In: Bancroft JD, Turner DR. Theory and practice of histological techniques. 4th ed. Churchill Livingstone, New York 1996: 99-112.

60. Sun Y, Oberley LW, Li Y. A simple method for clinical assay of superoxide dismutase. Clin Chem. 1988; 34(3): 497-500, indexed in Pubmed: 3349599.

61. Tamaddonfard E, Farshid AA, Ahmadian E, et al. Crocin enhanced functional recovery after sciatic nerve crush injury in rats. Iran J Basic Med Sci. 2013; 16(1): 83-90, indexed in Pubmed: 23638296.

62. Tkalec M, Stambuk A, Srut M, et al. Oxidative and genotoxic effects of $900 \mathrm{MHz}$ electromagnetic fields in the earthworm Eisenia fetida. Ecotoxicol Environ Saf. 2013; 90: 7-12, doi: 10.1016/j.ecoenv.2012.12.005, indexed in Pubmed: 23352129.

63. Tomassoni D, Di Cesare Mannelli L, Bramanti V, et al. Treatment with acetyl-L-carnitine exerts a neuroprotective effect in the sciatic nerve following loose ligation: a functional and microanatomical study. Neural Regen Res. 2018; 13(4): 692-698, doi: 10.4103/1673-5374.230297, indexed in Pubmed: 29722322.

64. Uthayathas S, Karuppagounder SS, Thrash BM, et al. Versatile effects of sildenafil: recent pharmacological applications. Pharmacol Rep. 2007; 59(2): 150-163, indexed in Pubmed: 17556793.

65. Vakharia KT, Lindsay RW, Knox C, et al. The effects of potential neuroprotective agents on rat facial function recovery following facial nerve injury. Otolaryngol Head Neck Surg. 2011; 144(1): 53-59, doi: 10.1177/0194599810390892, indexed in Pubmed: 21493387.

66. Wang $Y$, Shan Q, Meng Y, et al. Mrpl10 and Tbp are suitable reference genes for peripheral nerve crush injury. Int J Mol Sci. 2017; 18(2), doi: 10.3390/ijms18020263, indexed in Pubmed: 28134789.

67. Wilson ADH, Hart A, Wiberg M, et al. Acetyl-I-carnitine increases nerve regeneration and target organ reinnervation: a morphological study. J Plast Reconstr Aesthet Surg. 2010; 63(7): 1186-1195, doi: 10.1016/j.bjps.2009.05.039, indexed in Pubmed: 19664977.

68. Wilson ADH, Hart A, Brannstrom T, et al. Primary sensory neuronal rescue with systemic acetyl-L-carnitine following peripheral axotomy. A dose-response analysis. Br J Plast Surg. 2003; 56(8): 732-739, doi: 10.1016/j.bjps.2003.08.005, indexed in Pubmed: 14615246.

69. Xia Z, Tian X, Kong W, et al. Effects of L-carnitine on liver injury in rats and its impact on blood lipids. Int J Clin Exp Med. 2018; 11(9): 9768-9773.

70. Yanardag R, Ozsoy-Sacan O, Ozdil S, et al. Combined effects of vitamin $C$, vitamin $E$, and sodium selenate supplementation on absolute ethanol-induced injury in various organs of rats. Int J Toxicol. 2007; 26(6): 513-523, doi: 10.1080/10915810701707296, indexed in Pubmed: 18066967.

71. Yildirim AE, Dalgic A, Divanlioglu D, et al. Biochemical and histopathological effects of catechin on experimental peripheral nerve injuries. Turk Neurosurg. 2015; 25(3): 453-460, doi: 10.5137/10195149.JTN.12852-14.2, indexed in Pubmed: 26037187.

72. Yuan W, Feng X. Immune cell distribution and immunoglobulin levels change following sciatic nerve injury in a rat model. Iran J Basic Med Sci. 2016; 19(7): 794-799, indexed in Pubmed: 27635205.

73. Yüce $S$, Cemal Gökçe E, Işkdemir A, et al. An experimental comparison of the effects of propolis, curcumin, and methylprednisolone on crush injuries of the sciatic nerve. Ann Plast Surg. 2015; 74(6): 684-692, doi: 10.1097/SAP.0000000000000026, indexed in Pubmed: 24317243.

74. Zhang Z, Chopp M. Neurorestorative therapies for stroke: underlying mechanisms and translation to the clinic. Lancet Neurol. 2009; 8(5): 491-500, doi: 10.1016/s1474-4422(09)70061-4.

75. Zhang Q, Nguyen $P, X u$ Q, et al. Neural progenitor-like cells induced from human gingiva-derived mesenchymal stem cells regulate myelination of schwann cells in rat sciatic nerve regeneration. Stem Cells Transl Med. 2017; 6(2): 458-470, doi: 10.5966/sctm.2016-0177, indexed in Pubmed: 28191764.

76. Zochodne DW. The challenges and beauty of peripheral nerve regrowth. J Peripher Nerv Syst. 2012; 17(1): 1-18, doi: 10.1111/j.15298027.2012.00378.x, indexed in Pubmed: 22462663. 